\title{
JOVENS NA DITADURA E PÓS-DITADURA MILITAR BRASILEIRA: ESCRITAS EM CIÊNCIAS HUMANAS
}

\author{
Cynthia Machado Campos* \\ ccampos@essex.ac.uk
}

\begin{abstract}
RESUMO: A partir dos anos 60 do século XX a literatura em humanidades começou a falar sistematicamente sobre jovens no Brasil. Foi um período em que o jovem apareceu na cena politica brasileira, sobretudo em protestos, resistências e atuações diversas relacionadas a ditadura militar. Este e um trabalho que busca perceber as associações feitas entre jovem/violência ou jovem/rebeldia nas ciências humanas brasileiras. A pesquisa histórica acompanhou as mudanças de enfoque procedidas a partir dos anos 60, evidenciando mudanças de concepção, abordagens e formas de percepção de jovens, seus conflitos e comportamentos nas cidades. O conceito "alteridade" ganhou importância na pesquisa bibliográfica, com tentativas de pontuar quem é o "outro" do jovem, especialmente quando questões de identidade emergem, em diferentes momentos históricos e diferentes abordagens.
\end{abstract}

PALAVRAS-CHAVE: Jovens, Ditadura militar, Ciências Humanas.

\section{Jovens na ditadura militar}

Na década de 60 e nos anos que a seguiram no Brasil publicaram-se livros e artigos que deram visibilidade ao jovem. Esse interesse significou que o jovem esteva não apenas aparecendo na cena política, mas também literária, sociológica e antropológica. O “jovem” naquele momento passava a ser não apenas "agente político", mas também objeto de estudo

* Pós Doutoramento na University of Essex - Doutorado em História pela Universidade Estadual de Campinas (1998), parte deste realizado na Universidade Livre de Berlin. 
das ciências humanas e sociais, figurando nos textos acadêmicos com mais frequência do que anteriormente.

Na década de 60 e 70 se constituíram novas formas de atuação da juventude, tanto em termos políticos como culturais. As notícias e artigos de jornais evidenciaram sistematicamente que em cidades e conjunturas diferenciadas os jovens estiveram presentes como agentes ou atores, no palco de atuações diversas construído sobre a paisagem urbana. Ao mesmo tempo num movimento que evidenciava indistinção entre discursos e práticas, textos científicos e literários sobre a atuação de jovens foram produzidos por cientistas sociais. Referindo-se aos anos 60 a literatura sociológica fala na "década que pertenceu aos jovens", no "jovem como agente político" e na existência de um "poder jovem" na sociedade brasileira (Poerner, 1979). Não apenas no Brasil há uma tendência nas abordagens das ciências humanas em considerar essa década como aquela em que o "jovem aparece na cena política". i

No início dos anos 60 apareceram trabalhos que demonstraram a "presença da juventude", ou do "poder jovem”, relacionados a uma participação política efetiva. O tema também despertava atenções de educadores e orientadores educacionais que ensaiavam formas de "orientar jovens", tratando de "problemas individuais e de grupo" para buscar a “formação da personalidade, numa perspectiva humanista" (Baquero \& Frantz, 1972).

O interesse pela participação de jovens na política seu poder e suas possibilidades revolucionárias estava sendo estimulado por textos de autores russos traduzidos no Brasil, reunidos em uma coletânea intitulada "A rebelião da juventude na URSS". Essa coletânea trazia à discussão temas tais como a importância da exteriorização dos ideais e dos sonhos pelos jovens, os conflitos de geração e as possibilidades da literatura "fazer uma rebelião". Além disso, esses textos que circulavam entre grupos de jovens, evidenciavam imagens de jovens associados à música, família, artes, forças armadas e crimes; como no caso da União Soviética e da juventude comunista (Balashov, 1963).

Um dos trabalhos que estimulou a "rebelião da juventude" foi de um jornalista e estudante de direito que apresentava a Universidade Brasileira como lugar onde se "moldam consciências e mentalidades" a respeito dos problemas do país. Ressaltava a 
importância dos universitários comportarem-se de forma "nacionalista e progressista" no espaço universitário, e não como "policiais-delatores", com o objetivo de manter mais tarde os mesmos comportamentos como cidadãos. Enfatizava o "cunho social" da rebelião da juventude, embora essa pudesse estar presente também em aspectos "exteriores e individuais" como, por exemplo, no vestuário. O conflito de gerações era entendido como "agente cabalístico" da revolta, embora não fosse considerado elemento explicativo. Os "velhos", como pais, professores ou governo, estariam sendo "desmitificados" pele rebelião, da mesma forma que se "desmistifica a figura paterna" na adolescência, "adotando-a como antítese". Estabelecia-se ali a relação do jovem com o "outro": o conflito de gerações estaria agora se transformando numa "rebelião da juventude", quando o "velho" deixaria de ser "quadrado", para se transformar em "reacionário". As universidades seriam "guardiãs de dogmas", "conspiradoras do silêncio" e mantenedoras "da juventude na clausura". Existiriam "estruturas paralisantes e retrógradas" na sociedade e os "inimigos da juventude" seriam as ditaduras (Poerner, 1979, p. 33, 37, 38, 42, 43).

A "presença da juventude" também era evidenciada nos livros e textos vinculados à ala mais progressista da Igreja. Os jovens estariam, conforme um desses livros, nos grupos de base da igreja no Rio de Janeiro, São Paulo, Belo Horizonte e nas "mais de trinta pastorais de juventude" espalhadas em “diferentes pontos do país”. Esses grupos eram considerados os mais "engajados e conscientizados", e teriam como "missão religiosa dialogar com a juventude". O livro evidenciava que o jovem no momento de início da sua “integração à sociedade" estava sendo tratado como "problema", "estorvo" ou "ameaça"; em razão da sua rebeldia, inconformismo, alienação e agitação. Os textos propunham que a sociedade não desonrasse a juventude, mas que a tratasse como "solução e esperança", "renovação e superação" dos problemas. Considerava que estaria crescendo a violência e a repressão policial sobre os estudantes não apenas no Brasil como em toda a América Latina, como manifestação de "ditaduras fascistas". Entretanto os "movimentos estudantis" estariam se tornando cada vez mais políticos, e a "rebelião da juventude" estaria caminhando para formas "mais avançadas" como a participação decisiva na "derrubada das ditaduras” (Equipe “Alfa e Omega”, 1968, p. 5, 7, 8, 11, 15, 16). 
Uma coleção de textos publicada no Rio de Janeiro no final dos anos 60, constituída por traduções de autores norte-americanos, alemães, franceses e ingleses; propunha uma "sociologia da juventude" relacionada à necessidade de por fim a certo "estado de coisas" presentes nas universidades brasileiras. Esse "estado de coisas" seria o "tradicionalismo e a imitação aos modelos estrangeiros". Um "esforço renovador" deveria apontar para o "desenvolvimento" já que esse era consenso, como saída para a superação da situação contrária, o "subdesenvolvimento", da qual se teria tomado consciência recentemente. Já que a imitação era um dos grandes "problemas" para as ciências humanas da época, vinham agora os textos de ciências sociais buscarem "uma interpretação mais adequada" à realidade brasileira (Britto, II, 1968).

Tudo leva a crer que "preocupações sociológicas" com os jovens estavam sendo criadas no Brasil dos anos 60, pois no caso brasileiro poucos estudos ocupavam-se do assunto anteriormente. A "sociologia da juventude" foi significativa por ter sido uma das fundadoras das preocupações que influenciaram outros trabalhos no Brasil, que apareceram e cresceram em número e importância ao longo dos anos $70^{\mathrm{ii}}$ e $80^{\mathrm{iii}}$. A "sociologia da juventude" dialogando com trabalhos que pensavam a "juventude" nos anos 60, com os enfoques teóricos adotados e com a conjuntura da época, pôde inaugurar possibilidades da temática "juventude" ser abordada historicamente.

Além de preocupações em relacionar seus artigos com situações do "subdesenvolvimento" brasileiro, a obra "sociologia da juventude" pretendia empreender um movimento na direção de uma "sociologia diferencial". O objetivo era dar conta do "grupo humano heterogêneo juventude", já que "conceitos globais" teriam tendências “imprecisas e generalizantes". Esta sociologia pretendia fazer uma revisão no conceito "geração" que estaria sendo utilizado não apenas na linguagem comum, mas também como "modelo de sucessão das idades na estrutura social". Conforme a introdução dessa obra escrita por Sulamita de Britto, o conceito "geração" não seria adequado à análise, pois envolveria noções de "períodos sucessivos de desenvolvimento social" e de "espíritos de época" (Britto, 1968, II, p. 9)

A noção de "espírito de época" associada à de "geração" parece ser um elemento importante para a percepção de como a categoria "juventude" vinha sendo tratada em Hist. R., Goiânia, v. 18, n. 2, p. 247-274, jul. / dez. 2013 
termos de alteridade, num período anterior ao aparecimento da "sociologia diferencial". Na “juventude" estaria a possibilidade de transformação, de mudança, ou ainda conforme linguagem da época de "renovação do espírito". Entretanto ao mesmo tempo um "outro" espírito estaria "modelando" a geração jovem, um “espírito da época anterior". Questionando a noção "global" de época e a possibilidade de "reconstituir" um "espírito de época" o texto introdutório à sociologia da juventude falava das dificuldades que teriam os trabalhos que abordassem apenas uma minoria de pessoas, e que fossem incapazes de atingir a "mentalidade real" do jovem comum. Uma "amostragem rigorosa" seria necessária quando se fizesse uma pesquisa de opinião, para colocar as bases de uma "classificação tipológica" da qual seriam deduzidos "tipos básicos" ou "grupos formadores de estrutura". Importante aqui evidenciar a linguagem que busca conferir cientificidade à sociologia através de palavras como "reconstituir', "rigor" da amostragem e "realidade" da mentalidade. Essa linguagem também denota influências do estruturalismo quando fala em "grupos formadores de estrutura", e da abordagem das "mentalidades", muito em evidência na época (Britto, 1968, II, p. 10).

Alguns trabalhos de "sociologia diferencial da juventude" tentando demonstrar que mesmo diante de padrões impostos pelos meios de comunicação de massa nem toda a população juvenil manifestava os mesmos comportamentos e atitudes, enfatizavam a necessidade de inserir os estudos sobre jovens numa dinâmica de classes. Argumentavam que a estratificação social bem como a diferença étnica estariam presentes na socialização e educação dos jovens. Nessa perspectiva os jovens foram estudados tendo como referência as oposições classe superior, média e baixa. Outras oposições apareceram na nova sociologia da juventude, como aquelas que identificam uma "subcultura juvenil”, , "cultura juvenil", "contracultura" ou ainda "várias culturas juvenis", todas opostas ao "mundo adulto". As oposições poderiam se manifestar por "tolerância e favorecimento" dos adultos em relação às “culturas juvenis”, por um "caráter negativo" ou ainda por uma "imitação deformada do mundo adulto" (Chinoy, 1973, p. 11).

Os trabalhos continuavam falando na "singularidade" dos jovens universitários em relação à população em geral, evidenciada pela informação universitária abstrata, pela “consciência" da necessidade de uma participação política e pela educação para a política. 
Entretanto verificavam a inexistência de uma "chance real" de que tal participação se efetivasse (Chinoy 1973 p. 12). Quando as preocupações se voltavam para o estudo de "formas institucionalizadas e formalizadas da juventude nas sociedades modernas" o tema era relacionado aos estudos que abordavam classes sociais e suas "formas de organização". Nessa perspectiva os "grupos juvenis", a vida "coletiva" juvenil dos Kibutzim em Israel, e as "organizações" juvenis revolucionárias "vermelhas" na China também eram contrapostos à "sociedade dos adultos". Ao olharem para o movimento estudantil, a discussão dos sociólogos tendia a fundamentar-se no conceito de ideologia, à medida que se perguntavam acerca da existência de uma "ideologia estudantil", “ideologia universitária" ou "prática estudantil". Os trabalhos concluíam afirmando que por diversificadas vivências que integravam a vida universitária os estudantes não estabeleceriam laços sólidos que pudessem caracterizar a existência de grupos ou classes, mas apenas formas "frouxas" de agrupamento, chamada “agregados” (Britto, 1968, IV, p. 11, 12, 43, 44)

O referencial "classe" continuava pautando as discussões, problematizando questões como a de que os estudantes nunca poderiam colocar o "sistema em questão", pelo simples fato de serem estudantes universitários detentores de privilégios culturais. Os estudantes eram aqui pensados e problematizados numa perspectiva própria das abordagens sindicais da época, com preocupações corporativistas de melhoria da condição de vida estudantil. Também apareciam referências às preocupações políticas mais amplas dos estudantes, que apenas seriam atingidas caso transpusessem os muros da universidade e se associassem a "outros" segmentos de classe.

Essas análises que tomam como fundamento os referenciais classe, etnia, cor, cultura, grupo juvenil ou jovem, ideologia ou consciência; tendem a pressupor sempre um oposto. Esse oposto se constituiria na classe antagônica, no grupo étnico ou de cor diferenciada, nos adultos, nas famílias burguesas ou na própria burguesia. O oposto ou "outro" tinha um lugar, e esse lugar não estava na consciência ou na ideologia, mas naquilo que se encontrava fora dela, provavelmente no real. O "lugar" do "outro" era o "lugar do real", e não o "lugar" da consciência, da ideologia ou ainda da linguagem. A noção de consciência tinha naquele momento o mesmo significado de ideologia, vinculando-se à noção de real ou de classe. Entretanto a consciência não era considerada como parte

Hist. R., Goiânia, v. 18, n. 2, p. 247-274, jul. / dez. 2013 
integrante do real ou da classe. Ideologia (ou consciência) seria uma espécie de "outro" oposto (ou não) ao real. A consciência ou ideologia de classe era considerada oposta à "outra" consciência ou ideologia: a da classe antagônica. O entendimento do "outro" era parte de relações pautadas em antagonismos, ou em relações conflitantes e contraditórias entre classes sociais.

Como os trabalhos de sociologia da juventude dos anos 60 tinham como interlocutores internacionais os trabalhos de Habermas $^{\mathrm{v}}$ e Bourdieu ${ }^{\mathrm{vi}}$, as formulações teóricas desses autores eram foco de debate acerca da atividade dos jovens. Em um texto escrito para os 70 anos de Marcuse em 1968, Habermas falava em grupos de estudantes universitários e secundaristas como "potenciais de protesto" direcionados para "uma nova zona de conflito". A “zona de conflitos” estaria localizada nos meios de comunicação de massa, e tenderia a ocupar o lugar da oposição de classes. Habermas não vinculava "estudantes" necessariamente às "classes" ou interesses decorrentes de sua posição social, mas a um "status" favorecido ou privilegiado. Exemplificava a situação afirmando que alguns estudantes de áreas sociais, históricas ou linguísticas não se identificariam com a consciência tecnocrática ${ }^{\text {vii }}$.

Os conflitos ou oposições tanto para Habermas como para Bourdieu, estariam acontecendo no âmbito da ideologia, mas estabeleceram-se divergências entre os dois autores quanto ao entendimento desse conceito. Enquanto Habermas abordava a ideologia como um "conflito entre racionalidade técnica e potencial de protesto de estudantes", Bourdieu levava em conta a "apreensão indireta ou simbólica do real pelos universitários", fossem professores ou estudantes. Para Bourdieu haveria um "relacionamento" certamente conflituoso que uniria ideologias àquilo que chamava de "significação objetiva das condutas" (Bourdieu / Britto, 1968, IV, p. 83).

Outra tendência nos trabalhos da época ligados à sociologia da juventude foi a abordagem da "personalidade juvenil". Um desses estudos traduzidos porque era considerado como de significativa importância para referenciar trabalhos no Brasil, tratava de estudar a "ansiedade" como resultante de um conflito próprio do jovem-indivíduo com a sociedade. Afirmava que o jovem deveria "aprender a se ajustar emocionalmente" ao “impacto dos controles sociais" exercidos por pais, parentes, professores, empregadores e 
pela cultura em geral. A "personalidade" era considerada uma "marca individual" mais ou menos constante e inscrita no comportamento, própria do processo de socialização. Parece que o elemento "constância" era aqui importante para o entendimento da "personalidade particular do indivíduo". Da personalidade se distinguiam dois aspectos considerados ambos de natureza emocional. O primeiro "de natureza genética" e relacionado a uma história individual, era entendido como "mais importante" e o segundo "de natureza cultural" era considerado "segunda modalidade de diferenciação da personalidade". O que distinguiria um indivíduo dos demais na sociedade seria o comportamento manifesto como expressão da “personalidade particular” (Davis / Britto, 1968, II, p. 29, 38, 39, 40).

Em termos de abordagem da "ansiedade juvenil" o que é significativo evidenciar aqui é que tanto a noção personalidade quanto de sociedade eram entendidas como elemento fixos, mais ou menos constantes. Também cabe dar visibilidade à hierarquização feita entre os "elementos explicativos" da personalidade: a "história individual" vinha em primeiro lugar com forte conteúdo genético, e a "cultura" ficava em segundo plano.

A noção de personalidade era explicitada no trabalho de Ralph Linton, um antropólogo norte americano muito lido no Brasil na época ${ }^{\text {viii }}{ }_{\text {sobretudo pelos sociólogos }}{ }^{\mathrm{ix}}$, publicado pela primeira vez em português em 1967. O trabalho buscava inter-relações entre indivíduo, sociedade e cultura; lançando mão de conhecimentos de psicologia, sociologia e antropologia. Falava numa "nova ciência da conduta humana" que poderia explicar a aceitação ou rejeição de uma novidade (ou coisa nova) por aquilo que entendia como "personalidade dos membros de uma sociedade". Considerava que a "personalidade" era "formada" a partir de "relações interpessoais" e que um fator importante na sua compreensão era a referência às "posições" que os indivíduos ocupam no "sistema estrutural" da sociedade ou na estrutura de organização cultural. É importante evidenciar que expressões como “organização cultural”, "posição do indivíduo na estrutura social”, "sistema social", e "personalidade", a exemplo dos textos vinculados à "sociologia da juventude" no Brasil, evidenciavam a importância atribuída a certas noções de "permanência", de "coisas fixas", de "constância". Era essa uma tônica dos discursos das áreas de ciências humanas e sociais na época (Linton, Cultura e personalidade, p. 10-13).

Hist. R., Goiânia, v. 18, n. 2, p. 247-274, jul. / dez. 2013 
No início da década de 70 a juventude foi tratada como "categoria histórica e social" por um trabalho da Universidade de São Paulo que teve grande repercussão no Brasil. Contestava-se a noção de "geração" relacionada à busca de identidade. O "outro" da geração jovem não seria uma "outra geração", já que a tensão não estaria equacionada nesse tipo de relacionamento. A sociedade seria o "marco da referência à contestação" da juventude que se afirmaria como "categoria" nesses confrontos. À medida que se afirmasse um "movimento da juventude", este estaria expressando a "consciência jovem" dos conflitos próprios do sistema. A autora demonstrava grande influência das análises das sociedades de classes, e pautava na noção de ideologia a sua abordagem da juventude. Também deslocava o foco das atenções da noção de "geração" para a noção de "sociedade": a sociedade seria o lugar do conflito e, portanto da alteridade. O movimento da juventude foi estudado conforme os referenciais sociológicos da época, como "movimento organizado" evidenciando uma associação feita entre a noção de "consciência de classe" e a noção de "organização". O mesmo trabalho contesta o uso do conceito "contracultura" que considera de "difícil definição", correspondente a "uma representação intelectual incipiente", sem "estrutura definida" e, sobretudo "sem ideologia clara". A contracultura para a autora seria uma "ante-ideologia", algo do âmbito da "criatividade" (Foracchi, 1972).

No Brasil dos anos 70 já estava sendo lido pelos intelectuais e jovens universitários o livro de Theodore Roszak, clássico da contracultura publicado pela primeira vez no Brasil em 1972. Certamente em razão da polêmica em torno dessa noção no final da década e vinculada a uma conjuntura de abertura política no regime militar, a "contracultura" enquanto "valores, práticas e comportamentos", foi tratada como "expressão da alienação produzida pelo regime militar" por um artigo publicado em "Ensaios de Opinião". A categoria "geração" estava ali presente, pois o artigo intitulava-se "Geração AI-5" (Martins, 1979, p. 72-102).

Discutindo "ideologia" ou "mentalidades" a sociologia da juventude particularmente no âmbito universitário de São Paulo, tendia a pressupor a existência de um “outro" externo ao jovem, diferenciado, antagônico e oposto àquilo que pode ser considerado o "mesmo", na concepção de Foucault ${ }^{x}$. Esse “outro" se constituiria num grupo 
social, numa classe ou numa geração, essa última baseando-se na existência de novas ou velhas gerações. O jovem era abordado a partir da noção de "cultura", como as "subculturas juvenis", a "contracultura", a "cultura dominante" ou a "cultura adulta". O "outro" do jovem era representado pelas instituições como a família, escola ou sociedade capitalista.

\section{Jovens na pós-ditadura militar}

\subsection{Nas ciências humanas e sociais}

Talvez fosse importante evidenciar que questões referentes aos jovens têm se constituído numa grande maioria de trabalhos relacionados a problemáticas urbanas. Esse foi o caso de trabalhos de sociólogos e filósofos nos anos 80, que começaram a trazer a temática da violência para o debate vinculando-a a noção de "cidade" e "juventude" (Da Matta \& Paoli \& Pinheiro \& Benevides, 1982), (Fausto, 1984), (Morais, 1985), (Odalia, 1986), (Pinheiro, 1983), (Schneider, 1982). Estudos se dedicaram a estudar a "violência original das grandes cidades" e as "consequências da violência na paisagem urbana" (Odalia, 1986, p. 9, 10). Ressaltava-se a "agressão ao menor nos grandes centros urbanos", como parte das "relações próprias da lógica industrialista". Identificavam-se situações de menores "trancafiados em casa, ameaçados pela vida nas cidades" ou "carentes e abandonados". Evidenciava-se a "ameaça e incômodo que constituíam os menores infratores" por sua "conduta perigosa". Atribuía-se as razões do "problema do menor" ao "fracasso familiar" e às "imigrações

frustradas" de menores com suas famílias para as cidades, dos quais $85 \%$ acabariam em Fundações para o Bem-estar do menor ou na prostituição (Morais, 1985, p. 64 - 66).

A categoria "marginalidade" também passou a ser associada à "delinquência juvenil" num trabalho que reconhecia que a "violência urbana" estava sendo tema cada vez mais presente na imprensa, na academia e nos meios políticos. As relações de "classe" estavam presentes na análise da autora do trabalho à medida que "marginalidade" foi associada à noção de "classe baixa". A autora divergia dos discursos oficiais e resultados das estatísticas considerando-os "ideologia da classe dominante". Demonstrava, ao contrário de tais estatísticas, que a "causa principal da delinquência" não seria a "falta de 
família ou de estrutura familiar", mas a pobreza. Argumentava para isso que mesmo menores empregados com baixos salários tendiam a infringir a lei (Schneider, 1982, p. 7-9).

Mesmo aqueles trabalhos que não propunham abordar especificamente questões de jovens, a temática aparece associada necessariamente à violência urbana. Tal foi o caso do trabalho de Boris Fausto publicado em 1984. Tratando do final do século XIX e início do XX o estudo deteve-se na "transformação da criança em menor", assunto que já vinha sendo abordado por Mariza Corrêa (Correa / Fausto, 1984, p. 80). A questão discutida era que o menor passou a ser considerado no final dos anos 20 e início dos anos 30 do séc. XX, "predisposto e com tendências ao crime" (Fausto, 1984, p. 80). Outro trabalho organizado pelo sociólogo Paulo Sérgio Pinheiro demonstrava que os "embriagados, vadios, capoeiristas e desordeiros" do séc. XIX eram sobretudo jovens sobre os quais eram exercidos os "controles sociais". A frase seguinte é elucidativa nesse sentido: "Pega, mata, lincha!! O rapaz corre. É mulato escuro, franzino, aparenta ter, no máximo, 20 anos” (Pinheiro, 1983, p. 201, 210, 211, 227, 254, 255). Esse trabalho questionava as categorias utilizadas pelo aparelho repressivo que classificava os comportamentos como "desviantes" e afirmava que técnicas "educadoras" eram "amedrontadoras", e se dirigiam sobretudo aos “jovens” moradores de bairros populares (Pinheiro, 1983, p. 201, 210, 211, 227, 254, 255).

No Brasil dos anos 80, numa atmosfera de otimismo democrático de fim da ditadura militar e diante da constatação de um quadro em que a juventude estava sendo relacionada à "violência" e "marginalidade", um prêmio foi instituído por alguns jornais do Rio de Janeiro e São Paulo para trabalhos que elaborassem "propostas para a formação de jovens" em termos de "trabalho, saúde e educação". Esse concurso evidenciava preocupações com a necessidade de mobilização de alguns setores da sociedade e exercício de pressão sobre os governantes para instituírem políticas públicas voltadas para a juventude. A rebelião na adolescência era atribuída nessa chamada mobilizadora à "falta de um projeto de vida" e a “conflitos nas relações sociais". Foram publicados trabalhos de integrantes da área médica e de educadores que deram ênfase aos "fenômenos políticos econômicos e sociais" que "condicionariam" os problemas da juventude. Nos "problemas" eram constatadas “desinformação referente à sexualidade e reprodução, desconhecimento dos direitos de cidadão, influência negativa dos meios de comunicação de massa, não valorização do 
trabalho e da produtividade, não reconhecimento da potencialidade dos adolescentes". O trabalho terminava propondo a criação de um Conselho de Atenção à Juventude ligado ao Ministério da Cultura (Adamo, 1987, p. 15-49, 171).

Ainda nos anos oitenta trabalhos como o da filósofa Olgária Mattos (Matos, 1981) e da jornalista e professora de letras Heloisa Buarque de Hollanda (Hollanda, 1986) difundiam uma nova cultura jovem e participativa que teria sido criada em maio de 68 na França e nos anos 60 no Brasil, antes do Ato Institucional n.5. Esses trabalhos foram bastante lidos na época pelo tipo de publicação - uma coleção de bolso que circulava por preços acessíveis nas Universidades e outros espaços frequentados por jovens. Um desses trabalhos de "primeiros passos" foi o do sociólogo/antropólogo Carlos Alberto Messeder Pereira, que considerava a "contracultura" não mais como de "difícil definição", como “ante-ideologia", “ante-cultura" ou “expressão de alienação". Essas interpretações, próprias da época em que a noção de contracultura começou a circular no Brasil nos anos 70, passaram a ser entendidas agora como "novo estilo de mobilização e contestação social", vinculado às camadas médias e altas da população, diferenciada da tradicional mobilização da esquerda. A “contracultura" era ali tratada como "ascensão de um poder jovem ou de um espírito juvenil", de "contestação radical” ao sistema como "movimento social libertário", "catalisadora e questionadora" e inauguradora de um "estilo, de um modo de vida", de uma "cultura underground"xi

Herdeira da "juventude transviada", das "gangues", dos "inocentes provocadores" e dos "rebeldes sem causa"xii a contracultura passou a ser compreendida como movimento vinculado à música, arte e comportamento. Embora fiel a certos teóricos ou "gurus" mais velhos a contracultura teria fundado uma "consciência etária" e uma "oposição jovem-não jovem". O "outro" aqui continuava a ser o adulto identificado como "velho" ou "careta", não sendo mais o "reacionário" como evidenciado pelo entendimento do movimento de estudantes (Pereira, 1986, p. 7-24)

O autor apontava para um debate "quente" que girava em torno das noções de "alienação" e de "absorção pelo establishment" que envolveram o conceito de "contracultura" na época. Apontava também para a noção corrente de que seria necessária uma revisão do preconceito de inferioridade cultural, e para um entendimento da cultura no Hist. R., Goiânia, v. 18, n. 2, p. 247-274, jul. / dez. 2013 
plural. Com a conviç̧ão de que estaria "fora da cultura oficial" ou fiel à "filosofia do drop out", a juventude engajada na contracultura estaria buscando uma inversão do entendimento da cultura ocidental, apresentando a possibilidade de entendê-la como "doença". O homem envolvido com a cultura oficial (considerada "selvagem"), seria um "outro" "alucinado", um "confuso mental” ou um "indivíduo com a mente conturbada" (Pereira, 1986).

A problemática urbana continuava aparecendo em trabalhos sobre jovens na área de antropologia urbana ou social nos anos 80, agora com estudos como "contracultura e comportamento desviante na cidade de Porto Alegre" (Borloz, 1986) e sobre "tensão, alteridade, inquietude e estranhamento" no movimento Punk (Caiafa, 1985). Trabalhos na área da psiquiatria, psicologia, sexualidade e psicanálise também estavam se vinculando à temática dos jovens (Arries, 1987) (Fry \& Macrae, 1984) (Flandrin, 1988) (Guatarri, 1987).

Conforme a autora do trabalho sobre os Punks, eles teriam surgido nos "becos escusos e suburbanos do Rio de Janeiro" no ano de 1982. Teriam aparecido também nos subúrbios de São Paulo. O texto falava nos Punks como "guetos, bandos, gangues, maltas ou tribos nômades" que se deslocariam pelo "deserto" ou pela "estepe" com uma "pressa de movimentos" e "velocidade dos acontecimentos", num "clima de transgressão". Evidenciava o movimento como "cultura jovem", "instrumento de intervenção" com uma "função e força política", quando "impõe estranheza em qualquer lugar" que apareça. Os aspectos "desobediência, interferência e intensidade" do movimento bem como a "agressividade destrutiva" estariam imersos numa perspectiva de que "não haveria futuro" já que o mundo estaria no fim. Relacionava o movimento aos "rebeldes sem nenhuma causa, sem programa, sem estatuto, sem objetivo, sem orientação e sem propostas a serem apresentadas", mas com um som "bem definido": de música rock (Caiafa, 1985, p. 10-23, 137). O trabalho criticava as classificações das tribos (ou grupos) em tipos ou categorias criticando também as análises ou afirmativas "genéricas" de que a "crise gerou protestos". Fez outras críticas como à atribuição da explicação do aparecimento dos Punks à "canalização de frustração da juventude" e ao "fracasso das instituições em assimilar os jovens". Repensa a "negatividade nas abordagens", apontando para a possibilidade de recolocar "positivamente" os Punks, levantando questões que atualmente têm se constituído objeto das ciências humanas e sociais como o deslocamento constante, o nomadismo, a 
desterritorialização e o tribalismo ${ }^{\text {xiii }}$. Outras questões apareciam associadas ao movimento Punk como a ênfase no presente, na velocidade, e na ilusão de um segmento local homegeneizador - como nação, língua-. A autora apontava também para outras discussões vinculadas aos Punks como a multiplicidade das práticas, a variação em detrimento da autenticidade, o estrangeirismo para nunca pertencer, o estranhamento cultural e de si mesmo como prática, as trajetórias descontínuas, a afirmação das diferenças em uma sociedade não homogênea, a pluralidade, a multiplicidade e o exercício de desdobramento ou de ser múltiplo em múltiplos lugares (Caiafa, 1985, p. 10-23, 137).

Esse estudo já apontava nos anos 80 para concepções que iriam se afirmar a partir dos anos 90/2000 nas abordagens como à importância "política" do movimento Punk, a possibilidade de pensar a "estética" do movimento, a relação com a cidade, a história do rock como canção planetária e a questão da juventude nas sociedades industriais. O estudo também falava na produção de fenômenos que ultrapassavam as "histórias locais", "na importância da experiência (secreta) e do confronto nas abordagens", no "não uso das categorias de análise corriqueiras como classe, faixa etária, situação familiar (contra a autoridade do conceito)" nas análises sobre os Punks, na "invenção de novas entradas pela escritura." (Caiafa, 1985, p. 10-23, 137).

\subsection{Historiadores e jovens}

Até agora foram discutidas abordagens sobre jovens nos últimos anos no Brasil em áreas de ciências humanas e sociais para evidenciar de que forma aparece a relação dos jovens com os "outros". A partir de agora será feito um breve levantamento de algum material encontrado na área de história sobre temas que "atravessam" a temática juventude, mas que, com exceção de muito poucos trabalhos na área, não focalizam a temática como objeto central de pesquisa. Seria importante enfatizar que os trabalhos em história que abordam o tema são escassos, tratam do tema de forma periférica e começaram a aparecer com mais frequência a partir dos anos 80. Isso significa que antes dessa década a temática “juventude" não era preocupação central de historiadores brasileiros. Discussões de 
questões como identidade, alteridade, globalização e pós-modernidade foram encontradas com frequência nos textos de historiadores.

Além do fato de que na bibliografia existente na área de história a temática jovem não aparece com frequência, a tendência verificada nas abordagens é a mesma da área sociológica: os trabalhos sobre jovens estão associados às temáticas de violência. Verificou-se também que uma historicidade pode ser atribuída na relação do jovem com a violência nos trabalhos de história no Brasil. Recentemente um trabalho evidenciou essa mudança de enfoque ao problematizar a questão da "vida e arte"xiv em "situação limite" de internação em instituições para menores. A temática vincula-se às problemáticas que foram aparecendo no cinema brasileiro ligadas à violência urbana nos anos oitenta. Esse trabalho evidencia a mudança de tratamento do tema jovem/violência da década de 80 para o final dos anos 90. Localiza a discussão no fim do regime militar em meio a discursos com ressonância mundial que evidenciavam a marginalização e exclusão do jovem urbano, e que faziam críticas às instituições totais. Tais discussões se davam num momento em que estava sendo ampliado o espaço público e recriada a vida política no Brasil. A diferença de enfoque evidenciada pela autora do texto é que nos anos 80 abordava-se a violência exercida "sobre" o jovem, enquanto após o ano 2000 a tendência seria a abordagem da violência exercida “pelo” jovem (Botelho/Cancelli, 2004, p. 241-242).

Esse trabalho parece estar mais direcionado para tratar questões de cinema do que propriamente do jovem, embora tenha em poucas palavras atribuído uma historicidade à temática jovem/violência. Como esse é uma publicação de 2004, portanto um pouco mais recente do que outras aqui tratadas, tornou-se importante um percurso em alguns textos da área de historia do inicio dos anos 2000, para verificar como aparecem tais associações.

Em vários trabalhos de historia o jovem aparece vinculado à família, escola, arte ou música; como tema periférico, isto é, não é temática central de pesquisa. Quando se trata de família e escola há uma tendência a evocar o tema "infância", mas não o tema "juventude". Na Revista Brasileira de História que trata de família publicada em 1989, a criança ganha destaque enquanto os jovens não aparecem em nenhum dos artigos (Revista Brasileira de Historia, 1989). 
Encontramos apenas um trabalho publicado nos anos 80 na Revista Brasileira de História que ao tratar da ideologia e propaganda estatal no Estado Novo, demonstra como a imagem do jovem foi apresentada em lugar de destaque para sua atuação presente e futura. $\mathrm{Na}$ ideologia do regime o jovem "idealizado" representaria a brasilidade, participaria de passeatas e manifestações cívicas, teria proteção nos estudos e no trabalho com um bom desempenho, ajudando a organização da sociedade para aprimorar os objetivos do Estado Novo (Paulo, 1987, p. 113).

Essa imagem do jovem brasileiro assemelha-se as imagens de juventude difundida pelo fascismo italiano e nazismo alemão, quando a geração jovem passou a ser símbolo de virilidade, energia e possibilidades futuras da nação (Malvano / Levi \& Schimitt, 1996).

\section{Uma discussão (um pouco) mais recente sobre jovens}

Nos anos 90 no Brasil, os trabalhos sobre jovens continuaram trazendo para as discussões problemáticas urbanas, como o dossiê temático da Revista Estudos Feministas, organizado pela socióloga Wivian Weller, que teve grande circulação nas universidades brasileiras. Nesse dossiê todos os artigos publicados referiam-se aos jovens urbanos, ou evidenciam problemáticas urbanas em relação aos jovens, estivessem esses em São Paulo, Berlin, Salvador, Natal, ou nas Cidades da Praia e do Mindelo, nas ilhas de Cabo Verde (Weller, 1999, p. 103-177).

Esses trabalhos adotaram novos enfoques para as abordagens, colocando questões como a importância de que os estudos sobre juventude abordassem aspectos étnico-raciais e de classe, dando maior ênfase à perspectiva de gênero no que se refere a protestos ou resistências. Propunham a compreensão da "juventude como uma categoria que tem dois sexos" conforme palavras da organizadora do Dossiê. Apareceram ali preocupações em relacionar os trabalhos sobre jovens com as problemáticas "identidades", "raça", "corpo" "sexualidade", "visões de mundo", bem como com "o processo de construção da subjetividade". O conceito "subcultura" era tratado com certas reservas, evidenciadas na grafia “(sub) culturas juvenis” utilizada pela organizadora do dossiê. Permanece a ênfase no conceito de cultura, mas agora acrescido da problemática "gênero", naquilo que se 
configurariam em "culturas juvenis femininas". O trabalho ressentia-se da "invisibilidade feminina nas (sub) culturas juvenis', mobilizando-se para suprir essa "lacuna" e falando em “presença feminina” nessas culturas (Weller, 1999, p. 103-177).

As problemáticas urbanas continuavam aparecendo vinculadas a trabalhos que tratavam de violência nos anos 90, temática essa já bastante abordada nos estudos sobre juventude nos anos 80. Em alguns desses estudos a abordagem do assunto era muito semelhante àquelas verificadas nos anos 80, mas a tendência agora foi de mudança de enfoque. Um trabalho que pretendia "ser útil para planejadores, gestores de políticas públicas educadores e estudiosos" abordava os jovens como "aqueles que abriam alas para a sociedade de amanhã", que tomariam "lugar hoje na preocupação dos adultos". Esse trabalho associava os temas "juventude e violência" com as questões de "cidadania", localizando a questão na cidade do Rio de Janeiro. Envolvendo centros de estudos brasileiros sobre violência, institutos, fundações de pesquisa e a UNESCO; este trabalho, que pretendia "fornecer subsídios aos governantes para a implantação de políticas", foi interpretado pelos administradores destes órgãos como uma abordagem "das causas e fatores que exacerbam a violência". Os pesquisadores evidenciavam preocupações teóricometodológicas diferentes dos administradores, demonstrando seu interesse pelas falas, depoimentos e entrevistas de jovens entre 14 e 20 anos. Pretendiam mapear as "representações, atitudes, crenças, comportamentos, visões de mundo, valores, gostos, opções de vida, experiências, esperanças e desesperanças" da juventude, para demonstrar que a violência não seria “prerrogativa de jovens de classes populares” (Minayo, 1999, p. 7, $8,11,12)$.

Num número da Revista Brasileira de Historia que trata de crianças e adolescentes, os jovens são considerados da mesma forma que aparecem na sociedade: como "menores". Os artigos tratam em sua maioria de crianças e as discussões sobre jovens vinculam-se à justiça, poder judiciário, inimputabilidade penal e casas de correção (Revista Brasileira de Historia, 1999).

Trabalhos dos primeiros anos do séc. XXI no Brasil relacionaram a discussão da violência à cidadania e à democratização da sociedade de forma muito semelhante às abordagens feitas após o fim do regime militar. A diferença é que agora passaram a avaliar 
os resultados não satisfatórios da democratização no que se refere à justiça e direitos de certos setores da sociedade, aparecendo trabalhos que discutiram "crueldade" vinculada à "globalização" (Caldeira, 2002, p. 44). Novos olhares sobre o assunto foram lançados no início do novo século, com discussões sobre "microfísica da violência", incluindo o "gênero" nas abordagens referentes à classe ou etnia, com uma nova linguagem que falava em violência "simbólica", "sentimento" coletivo de insegurança, "representações" sociais da violência, "dramatização", "visibilidade" ou "espetacularização" da violência pelos meios de comunicação. Localizavam a questão num "mundo pós-moderno", evidenciando as "imagens" da criminalidade, o "pluralismo" jurídico e os "dispositivos" de violência. Aparece uma preocupação em abordar o "problema da alteridade cultural", vinculando-o ao "individualismo exacerbado", à "solidão narcisista" e à "massificação". Esse processo tenderia a "desfiliar" as pessoas, no sentido de romper contratos ou vínculos sociais, dilacerando dessa forma os laços entre o eu e o "outro" (Santos, 2002. p. 22-23).

Os temas urbanos continuam, mas os estudos agora tendem a se "localizar" falando em "lugar da violência" ou em "áreas de concentração" nas cidades (Cardia, 2002, p. 25), em bairros $^{\mathrm{xv}}$, em “quistos urbanos" não submetidos à lei (Adorno, 2002, p. 50), comandados pelo tráfico. Os jovens são "traficantes" e/ou "usuários" de drogas e "convidados a montar armas" (Zaluar, 2002, p. 32-38). Eles são estudados nos seus comportamentos, nas suas escolhas entre violência e emigração, essa última relacionada ao mundo globalizado (Pochman, 2002, p. 39). O tema da impunidade penal vem à tona e também o da tolerância da sociedade brasileira em relação aos linchamentos, aos grupos de extermínio, às práticas de agentes polícias. Tais preocupações aparecem em estudos que abordam o uso excessivo da força, a atuação violenta e o abuso da autoridade no envolvimento em práticas delituosas (Isumino, 2002, p. 48) e o monopólio estatal da violência (Adorno, 2002, p. 50). Os temas de rebelião nos presídios comandados pelo crime organizado também aparecem em trabalhos que discutem as cidades de São Paulo e Rio de Janeiro (Adorno, 2002, p. 50).

A forma pela qual os jovens aparecem nos trabalhos brasileiros da área de uma história recente não difere muito da forma como aparecem em outras áreas das ciências humanas aqui discutidas. Um estudo que aborda as questões de gênero na história insere a temática jovem na discussão sobre a "modelagem da diferença de meninos meninas" em

Hist. R., Goiânia, v. 18, n. 2, p. 247-274, jul. / dez. 2013 
escolas do século XIX. Esse trabalho aponta para a perspectiva da "fabricação e engendramento de sujeitos, de constituição de identidades plurais, múltiplas, mutantes e contraditórias" (Muniz / Swain, 2002, p.192). Trabalhos sobre jovens na área de história da educação abordam a temática de forma periférica quando tratam de escolas religiosas abordando a questão da educação de jovens para os padrões de civilidade e "fabricação de elites"xvi . Na esteira da educação um estudo sobre desdobramentos dos discursos da extensão rural em Santa Catarina nos anos 70/80 fala dos jovens rurais que frequentavam clubes para disciplinar suas práticas como os clubes $4 \mathrm{~S}^{\mathrm{xvii}}$.

Ainda numa aproximação da história com a antropologia na perspectiva da história cultural, alguns trabalhos no Brasil trataram recentemente da contracultura dos jovens. São eles: "Algumas considerações sobre as origens e a decadência da contracultura" (Biagi, 2005, p. 1593-1599); “A contracultura na América do Sol: Luiz Carlos Maciel e a coluna Underground" (Barros, 2003); e "O negócio é sintonizar e cair fora: os efeitos da contracultura na sociedade catarinense durante a década de 1970” (Silva, 2004). Outros trabalhos tratam de juventude e rebeldia nos anos 80 através da música dos Titãs ou dos jovens negros através do RAP (Dias, mimeo) (Souza, 2001, p. 223-243). O jovem vinculado à cultura popular no Brasil tem sido estudado por um historiador que aborda a violência dos "capoeiras" nas festas populares do Rio de Janeiro no século XIX (Soares/Cunha, 2002, p. 281-310), por uma historiadora que aborda Centros Populares de Cultura da União Nacional dos Estudantes - CPCs da UNE - e sua políticas culturais (Garcia, 2004, p. 127-162) e por um professor de história que fez um trabalho sobre cultura jovem dos anos 50 aos anos 80 (Brandão \& Duarte, 1990).

Políticos ligados à área do direito têm se interessado pelo tema como um trabalho que faz uma espécie de chamado ao engajamento dos jovens, a exemplo do que faziam alguns trabalhos publicados nos anos sessenta. Essa publicação evidencia a "atitude revolucionária juvenil no Brasil”, o "jovem como ator da cena política”, o "potencial da juventude" para influenciar mudanças, sua "criatividade" em movimentos como "os carapintada" do impeachment e na "ação autônoma" dos jovens na gestação de lideranças políticas. Preocupa-se com a "perspectiva de futuro dos jovens" com a criação de um “campo civilizatório de participação na construção da sociedade e do futuro da 
humanidade". Preocupa-se também com a questão da organização dos jovens para mudar a relação do homem com a natureza e com o jogo de inclusão e exclusão decorrente da disputa globalizada (Zaneti, 2001, p. 21-24 ).

Trabalhos que resultaram do engajamento político e da atuação do Partido dos Trabalhadores no poder também têm discutido jovens. Foi esse o caso de uma exaustiva pesquisa sobre juventude, que envolveu um corpo significativo de pesquisadores num amplo projeto vinculado ao Instituto da Cidadania e à Fundação Perseu Abramo, essa última instituída pelo Diretório Nacional do PT em 1996. Os "Retratos da Juventude Brasileira" interrogaram o papel dos jovens na transformação da sociedade brasileira e se destinaram a recomendar "formulações de políticas para esse segmento" (Abramo \& Branco, 2005). Através desse e de outros trabalhos que vinculam a questão dos jovens à cidadania parece ser possível pensar que quando se trata de propostas em relação aos jovens, há uma preocupação geral da sociedade para que o jovem não se identifique com possibilidades de violência. A sociedade teria um papel fundamental através da escola e de outros meios, como a mídia, no sentido de exercer uma intervenção sobre a juventude ${ }^{\mathrm{xviii}}$.

Nessa perspectiva um estudo na área de educação trata da construção e negociação de sentidos vinculados ao papel da mídia junto ao jovem, e do papel que essa exerce na construção de subjetividades. A mídia conforme o autor teria um papel de intervir sobre os jovens não apenas nos espaços tradicionais como família e escola, mas também nas tribos urbanas e nos movimentos sociais (Souza, 1997, p. 56).

$\mathrm{Na}$ área da sociologia dois artigos discutiram a temática vinculada também à educação, abordando cidadania, políticas sociais e ações públicas; com preocupações de como a sociedade estaria estruturando o futuro das novas gerações. Percebe-se nesses trabalhos uma tendência à abordagem histórica da questão, pois demonstra como o jovem vem atuando no espaço publico e como vem sendo representado na modernidade (Sousa, 2001, p. 51-78) (Sousa, 1999, p. 51-78).

\section{Finalizando}

Hist. R., Goiânia, v. 18, n. 2, p. 247-274, jul. / dez. 2013 
Partiu-se nesta pesquisa, de uma imagem negativa de jovens nos anos 60, que coincide com o período da ditadura militar brasileira e que pontuou os primeiros trabalhos sobre o tema publicados no Brasil. Alienação e violência são os temas mais discutidos nesta década. Muitos trabalhos deste período tratam de questões de ideologia, considerando fundamental a dicotomia entre ideologia (associada a noção de consciência), e o plano da realidade. $\mathrm{O}$ conceito de ideologia tende a vincular-se ao conceito de classe social, e as diferentes classes não só são entendidas em suas diferentes ideologias, como também em seus antagonismos e contradições. A noção de alteridade referente aos anos 60 foi discutida aqui na dimensão das abordagens teóricas da época, ou seja, dos conflitos entre classes sociais.

Nos anos 70 certos trabalhos continuam, como na década anterior, tratando das questões de classe social vinculadas a noção de ideologia, enquanto outros trabalhos evidenciam criticas a noção de geração como lugar de conflito nas abordagens sobre juventude. O movimento de jovens são entendidos numa perspectiva classista e de movimento organizado, envolvendo a noção de consciência de classe. Alguns trabalhos relutam em adotar o conceito de contracultura, argumentando que "contracultura" não se configuraria enquanto ideologia, mas ao contrario, seria uma ante-ideologia. Importante observar que nessa década os conceitos e categorias usados nas analises sobre jovens adquirem um caráter de permanência, de constância, de coisas fixas.

Nos anos 80, no final da ditadura militar brasileira, a temática juventude aparece associada sobretudo a noção de cidades, sobretudo de violência em grandes cidades industriais. Os textos costumam falar em "menor" no lugar de jovem, sobretudo em menores infratores. A categoria "marginalidade" é amplamente utilizada quando tratando questões de violência urbana que envolvem jovens de classes baixas ou da "pobreza". Falase também em comportamentos desviantes quando trata-se de jovens e vincula-se muitas destas noções à falta de projetos de vida. Poucos trabalhos apresentam uma visão um pouco mais afirmativa sobre jovens, como os trabalho que tratam de cultura jovem, de contracultura e de participação do jovem na politica. Entretanto, um trabalho encontrado sobre movimento punk nos anos 80 se coloca numa perspectiva mais positiva se comparado com os trabalhos publicados na mesma época, abrindo possibilidades para pensar o 
movimento punk na sua importância politica e na sua dimensão estética. Alguns dos trabalhos dos anos 80 resistem em inscrever suas analises num a perspectiva de classes, de faixa etária ou situação familiar. Entre historiadores as preocupações sobre o tema "juventude" começa a aparecer com mais frequência nesta década de 80, em meio a discussões de identidade, alteridade, globalização e pós-modernidade.

Nos anos 90 e no inicio do século XXI os temas continuam abordando identidades, tornando-se mais frequentes as questões de globalização, gênero e sexualidade vinculadas aos jovens. As discussões são ampliadas e envolvem jovens na família, na escola, nas arte e musica. São frequentes preocupações em abordar noções de corpo jovem e construção de subjetividades juvenis. Continua-se falando em violência numa dimensão diferente das décadas anteriores, ou seja, evidencia-se agora "dispositivos de violência" e "caráter simbólico da violência”. Recorre-se frequentemente às noções de sentimentos relacionados ao jovem e de alteridade. As discussões sobre cultura tornam-se lugar comum em diversas áreas das humanidades, e não apenas na área da antropologia como costumava ser anteriormente. As discussões pontuam necessidades de mobilizações da sociedade para que o jovem não se identifique com violência e grandes preocupações levantam-se no que concerne a intervenção da mídia sobre os jovens.

\section{Young People During the Brazilian Military Dictatorship and the Following Period: An Analyses of Human Science Publications}

ABSTRACT: In the early 1960s, social scientists and journalists in Brazil began for the first time to look at young people and youth culture. This was a time when the Brazilian youth appeared on the political scene, taking part in riots and other acts of protest whose purpose was to undermine the military dictatorship. In this article I will try to make clear the connections between young people and violence and rebellion as documented in contemporary Brazilian Social Science publications. My research investigates the changes in theory and methodology assumed by academics of the 1960s, emphasising the ways in which the perception of young people changed during the 1960s, and the changing behaviour of urban youth. The conception of 'otherness' became important during my 
biographical research. I attempted to determine who represented 'the other', or the unwelcome outsider, to young people at a time when youth identity was becoming so important.

KEYWORDS: young people, military dictatorship, humanities.

\section{NOTAS}

i Em Londres circulava a noção de "Student Power" através de publicações que popularizaram a expressão. (Cockburn \& Blackburn, 1969) (Nagel, 1969).

ii Nos anos setenta apareceram, entre outros, os seguintes trabalhos: Foracchi (1972), Martins (1979).

iii Nos anos 80, é possível encontrar um pouco mais de títulos sobre jovens ou que tratam de temas afins:

Da Matta \& Paoli \& Pinheiro \& Benevides (1982), Fry \& Macrae (1984),

Caiafa (1985), Matos (1981), Pereira (1986), Pinheiro (1983), Schneider (1982).

iv Os sociólogos da época costumavam referir-se aos jovens como "subcultura", como no caso de Ely Chinoy que falava em "subculturas estudantis" e, para se referir à delinquência juvenil, em "subculturas divergentes" (Chinoy, 1973, p. 550, 654).

${ }^{\mathrm{v}}$ Habermas publicou nessa coletânea um texto em coautoria com Friedeburg, Oehler e Weitz com o título de 'O comportamento político dos estudantes comparado ao da população em geral' (Britto, 1968, II, p. 115-132).

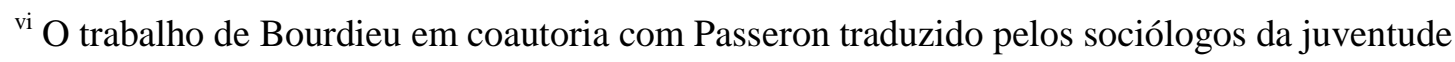
brasileiros foi 'O tempo e o espaço no mundo estudantil' (Britto, 1968, IV, p. 61 - 86).

${ }^{\text {vii }}$ A consciência tecnocrática, para Habermas, seria uma ideologia tecnocrática, que vinculada a um sistema de domínio público, diante da despolitização das massas. Tal ideologia encobriria as diferenças entre uma racionalidade técnica e as possibilidades de emancipação da sociedade. (Habermas, 1975, p. 331-332).

viii O trabalho tratado aqui é "Cultura e personalidade" que teve sua primeira edição brasileira em 1967. Importante evidenciar que um outro trabalho desse mesmo autor, 'O homem: uma introdução à antropologia', fora anteriormente bastante difundido nos meios acadêmicos, pois no início dos anos 70 já estava em sua nona edição brasileira. (Linton, 1973, Cultura e personalidade) (Linton, 1973, O homem: uma introdução à antropologia)

${ }^{\text {ix }}$ Um dos compêndios de sociologia muito lidos nas academias brasileiras era o trabalho de Ely Chinoy, que transcrevia excertos de Ralph Linton, e que em 1973 estava em sua terceira edição brasileira. (Chinoy, 1973).

${ }^{x}$ Foucault opõe o Mesmo ao Outro no prefácio da obra As palavras e as coisas. (Foucault, 1990).

${ }^{x i} \mathrm{O}$ "underground" aqui era entendido como um "mundo alternativo", um "outro lado da muralha" ou um "interstício do mundo desacreditado" (Pereira, 1986, p. 7-24). 
xii Alusão ao filme estrelado em 1955 por James Dean, dirigido por Nicholas Ray.

xiii A expressão teria aparecido num artigo, The Tribes of Britain, publicado na Revista Time, em Londres, em 24/10/1983. (Apud: Caiafa, 1985, p. 19).

${ }^{\text {xiv }}$ Ressalte-se que o que vinha sendo tratado em termos de "dominação/resistência" nos anos 80, é cada ver mais pensado em termos de "artes de fazer", ou de "estratégias cotidianas para lidar com o instituído”, abordagem essa inspirada na obra de Michel de Certeau. (Certeau, 1994).

${ }^{\mathrm{xv}}$ Zaluar localiza um estudo em três bairros do Rio de Janeiro: Copacabana, Tijuca e Madureira. (Zaluar, 2002, p. 32) .

${ }^{\text {xvi }}$ Um dos trabalhos trata da masculinidade no Colégio Catarinense em Florianópolis, onde estudavam e "eram fabricados" os filhos das elites de Santa Catarina. (Dallabrida, 2001). Outro trabalho trata dos jovens que estudavam no mesmo colégio e que deveriam se distinguir pelos padrões de civilidade e de prestígio para ocupar as posições privilegiadas na sociedade em Santa Catarina. (Souza, 2005).

xvii 4S significava saber, sentir, servir e saúde (Silva, 2002, p. 190-210)

xviii Um outro trabalho na mesma perspectiva das políticas públicas publicado pelo mesmo Instituto foi: Novaes \& Vannuchi (2004).

\section{REFERÊNCIAS}

ABRAMO, Helena Wendel \& BRANCO, Pedro Paulo Martoni. Retratos da juventude brasileira: análise de uma pesquisa nacional. São Paulo: Instituto da Cidadania/Ed. Fundação Perseu Abramo, 2005.

ABRIL CULTURAL. Os Pensadores. São Paulo: Victor Civita, 1975.

ADAMO, Fábio. Juventude: trabalho, saúde e educação. Rio de Janeiro: ForenseUniversitária, 1987.

ADORNO, Sérgio. 'Crise no sistema de justiça criminal' (Revista da Sociedade Brasileira para o progresso da Ciência, 2002).

ARRIÈS, Philippe \& BÉJIN, André (orgs.). Sexualidades Ocidentais. São Paulo: Brasiliense, 1987.

BALASHOV, Anatoly. et. Al. A rebelião da juventude na URSS. Rio de Janeiro: Ed. GRD., 1963.

BAQUERO, Godeardo \& FRANTZ, Theobaldo. Assim falam Eles e Elas: pesquisa dos problemas do adolescente brasileiro. Porto Alegre: Ed. dos autores, 1962.

BARROS, Patrícia Marcondes. 'A contracultura na América do Sol: Luiz Carlos Maciel e a coluna Underground’ (Pós-História, 2003).

BIAGI, Orivaldo Leme. 'Algumas considerações sobre as origens e a decadência da contracultura' (Fragmentos de cultura, 2005). 
BORLOZ, Alexis Acauan. Malucos: a contracultura e o comportamento desviante. Porto Alegre: UFRG, 1986. (Dissertação de Mestrado em Antropologia Social).

BOTELHO, Rosana. Ulhôa. Pixote e Vera: arte e vida institucionalizada (Cancelli, 2004).

BOURDIEU, Pierre. 'O tempo e o espaço no mundo estudantil' (Britto,1968, IV).

BRANDÃO, Antônio Carlos \& DUARTE, Milton Fernandes. Movimentos culturais da juventude. São Paulo: Moderna, 1990.

BRITTO, Sulamita de (org.). Sociologia da juventude, II: para uma sociologia diferencial. Rio de Janeiro: Zahar Editores, 1968.

BRITTO, Sulamita de (org.). Sociologia da juventude, IV: os movimentos juvenis. Rio de Janeiro: Zahar Editores, 1968

CAIAFA, Janice. Movimento Punk na cidade: a invasão dos bandos sub. Rio de Janeiro: Jorge Zahar Ed, 1985.

CALDEIRA, Teresa Pires do Rio. 'Violência, direitos e cidadania: relações paradoxais' (Revista da Sociedade Brasileira para o progresso da Ciência, 2002).

CANCELLI, Elizabeth(org.). Histórias de violência, crime e lei no Brasil. Brasília: Ed. UnB, 2004.

CARDIA, Nancy \& SCHIFFER, Sueli. 'Violência e desigualdade social' (Revista da Sociedade Brasileira para o progresso da Ciência, 2002).

CERTEAU, Michel. A invenção do cotidiano: artes de fazer. Petrópolis, Vozes, 1994.

CHINOY, Ely. Sociedade: uma introdução à sociologia. São Paulo, Cultrix, 1973.

COCKBURN, Alexander \& BLACKBURN, Robin (org.). Student Power: problems, diagnosis, action. London: Penguin Books/New left Review, 1969.

CORREA, Mariza. 'Antropologia e medicina legal. Variações em torno de um mito'. Caminhos cruzados. São Paulo, Brasiliense, 1982.

CUNHA, Maria Clementina. Carnavais e outras f®estas: ensaios de história social da cultura. São Paulo, Ed. da UNICAMP, 2002.

DALLABRIDA, Norberto. A fabricação escolar das elites: o ginásio catarinense na Primeira República. Florianópolis: Cidade Futura, 2001.

DA MATTA, Roberto \& PAOLI, Maria Célia \& PINHEIRO, Paulo Sergio \& BENEVIDES, Maria Victória. Violência Brasileira. São Paulo: Brasiliense, 1982.

DAVIS, Allison. 'A socialização e a personalidade juvenil' (Britto, 1968, II).

DIAS, Edson João Liberato. Cabeça de Dinossauro: juventude e rebeldia nos anos 80. (Mimeo).

ENSAIOS DE OPINIÃO, v.2, Rio de Janeiro: Paz e Terra, 1979.

EQUIPE “Alfa e Omega”. Juventude e presença: diálogos com a juventude. São Paulo, F.T.D. S.A, 1968. 
ESTUDOS FEMINISTAS. Florianópolis: UFSC, 1999.

FAUSTO, Boris. Crime e cotidiano: a criminalidade em São Paulo. São Paulo: Brasiliense, 1984.

FLANDRIN, Jean-Louis. O sexo e o ocidente. São Paulo: brasiliense, 1988.

FORACCHI, Marialice M. A juventude na sociedade moderna. São Paulo: Pioneira, 1972.

FOUCAULT, Michel. As palavras e as coisas: uma arqueologia das ciências humanas. São Paulo: Martins Fontes, 1990.

FRAGMENTOS DE CULTURA. 15(10). Goiânia: Instituto de Filosofia e Teologia/Sociedade Goiana de Cultura/ Universidade Católica de Goiás. Out. 2005.

FRY, Peter \& MACRAE, Edward. O que é homossexualidade. São Paulo, brasiliense, 1984.

GARCIA, Miliandre. 'A questão da cultura popular: as políticas culturais do Centro Popular de Cultura (CPC) da União Nacional dos Estudantes (UNE)’ (Revista Brasileira de História, 2004).

GUATTARI, Felix. Revolução Molecular: pulsações políticas do desejo. São Paulo: Brasiliense, 1987.

HABERMAS, "Técnica e ciência enquanto "ideologia"” (Abril Cultural, 1975).

HOLLANDA, Heloisa B. de \& GONÇALVES, Marcos A. Cultura e participação nos anos 60. São Paulo: Brasiliense, 1986.

ISUMINO, Wânia Pasinato \& NEME, Cristina. Violência urbana e graves violações de direitos humanos (Revista da Sociedade Brasileira para o progresso da Ciência, 2002).

LEVI, Giovanii \& SCHIMITT, Jean-Claude. História dos Jovens 2. São Paulo, Companhia das letras, 1996.

LINTON, Ralph. Cultura e personalidade. São Paulo: Mestre Jou, 1973.

LINTON, Ralph. O homem: uma introdução à antropologia. São Paulo: Martins, 1973.

MALVANO, Laura. 'O mito da juventude transmitido pela imagem: o fascismo italiano' (Levi \& Schimitt, 1996).

MARTINS, Luciano. 'A geração AI-5 - um ensaio sobre autoritarismo e alienação' (Ensaios de Opinião, 1979).

MATOS, Olgária C. F. Paris 1968: as barricadas do desejo. São Paulo: Brasiliense, 1981.

MINAYO, Maria Cecília de Souza et al. Fala Galera: juventude, violência e cidadania na cidade do Rio de Janeiro. Rio de Janeiro: Garamond, 1999.

MORAIS, Regis. O que é violência urbana. São Paulo: Abril Cultural/Brasiliense, 1985.

MUNIZ, Diva do Couto Gontijo. Meninas e meninos na escola: a modelagem das diferenças (Swain, 2000). 
NAGEL, Julia (org.). Student Power. London: Merlin Press. 1969.

NOVAES, Regina \& VANNUCHI, Paulo (org.). Juventude e sociedade: trabalho, educação, cultura e participação. São Paulo: Fundação Perseu Abramo/Instituto da Cidadania, 2004.

ODÁLIA, Nilo. O que é violência. São Paulo, Brasiliense, 1986.

PAULO, Heloisa Helena de Jesus. 'O DIP e a juventude - Ideologia e Propaganda Estatal (1939-1945)’ (Revista Brasileira de Historia, 1987).

PEREIRA, Carlos Alberto M. O que é contracultura. São Paulo: Nova Cultural/Brasiliense, 1986.

PINHEIRO, Paulo Sérgio (org). Crime, violência e poder. São Paulo, Brasiliense, 1983.

POCHMAN, Marcio. 'Violência e imigração internacional na juventude' (Revista da Sociedade Brasileira para o progresso da Ciência, 2002).

POERNER, Artur José. O poder jovem: história da participação política dos estudantes brasileiros. Rio de Janeiro: Civilização brasileira, 1979 (publicado pela primeira vez em 1968).

POS-HISTORIA: Revista de Pós-Graduação em História. v. 11. Assis, SP: UNESP. 2003

REVISTA BRASILEIRA DE HISTÓRIA: Brasil: do ensaio ao golpe. 24 (47). São Paulo: ANPUH, jan./jun. 2004.

REVISTA BRASILEIRA DE HISTÓRIA: família e grupos de convívio, 9(17). São Paulo: ANPUH/Marco Zero. set. 1988/fev. 1989.

REVISTA BRASILEIRA DE HISTÓRIA: infância e adolescência. 19(37). São Paulo: ANPUH/Humanitas. 1999.

REVISTA BRASILEIRA DE HISTÓRIA: instituições 7(14). São Paulo, ANPUH/Marco Zero, mar/ago.1987.

REVISTA CADERNOS CEOM: campo e cidade. n. 14. Chapecó, SC: Argos, 2001.

REVISTA CADERNOS CEOM: representações do corpo e da morte. Chapecó, SC: Argos, 2002.

REVISTA CATARINENSE DE HISTORIA: Fronteiras, n. 09, Florianópolis: ANPUH/ Dpto. História. dez. 2001.

REVISTA DA SOCIEDADE BRASILEIRA PARA O PROGRESSO DA CIENCIA: Ciência e Cultura. São Paulo: Imprensa Oficial, ano 54, n.1, jul/ago/set. 2002.

REVISTA DA POS-GRADUACAO EM HISTORIA DA UNB: Textos de Historia. Brasília, UNB, 2000. vol. 8, n. $1 / 2$.

REVISTA DE CIENCIAS HUMANAS. n. 26, Florianópolis: Ed. da UFSC, out. 1999.

REVISTA EDUCACAO \& REALIDADE: cultura, mídia e educação. 22(2), Porto Alegre: Faculdade de Educação UFRG, Jul/dez. 1997. 
SANTOS, José Vicente Tavares dos. 'Microfísica da violência: uma questão social mundial' (Revista da Sociedade Brasileira para o progresso da Ciência, 2002).

SCHNEIDER, Leda. Marginalidade e delinquência juvenil. São Paulo: Cortez, 1982.

SILVA, Claiton Márcio. 'Povo desenvolvido é povo limpo: o controle do corpo do jovem rural através dos clubes 4S, SC (1970-1985)' (Revista Cadernos CEOM, 2002).

SILVA, Paulo Valério M. O negócio é sintonizar e cair fora: os efeitos da contracultura na sociedade catarinense durante a década de 70. Florianópolis: UFSC, 2004. (Projeto de pesquisa em História).

SOARES, Carlos Eugênio Líbano. 'Festa e violência: os capoeiras e as festas populares na corte do Rio de Janeiro (1809-1890)' (Cunha, 2002).

SOUSA, Janice Tirelli Ponte. 'A juventude e o rompimento da tradição na constituição do espaço público’ (Revista Catarinense de História, 2001).

Humanas, 1999).

. 'Os jovens, as políticas sociais e a formação educativa' (Revista de Ciências

SOUZA, Ângela Maria. 'O movimento do RAP: do Bronx a Florianópolis' (Revista Cadernos CEOM, 2001).

SOUZA, Mauro Wilton. 'Juventude e os espaços sociais de construção e negociação de sentidos’ (Revista Educação \& Realidade, 1997).

SOUZA, Rogério Luiz de. Uma história inacabada: cem anos do Colégio Catarinense. São Leopoldo, RS: ed. UNISINOS, 2005.

SWAIN, Tânia Navarro (org.). 'Feminismos: teorias e perspectivas' (Revista da PósGraduação em História da UNB, 2000).

WELLER, Wivian (org.). 'Seção temática gênero e juventude' (Estudos Feministas, 1999).

ZALUAR, Alba. A guerra sem fim em alguns bairros do Rio de Janeiro (Revista da Sociedade Brasileira para o progresso da Ciência, 2002).

ZANETI, Hermes. Juventude e revolução: uma investigação sobre a atitude revolucionária juvenil no Brasil. Brasília: Ed. UNB, 2001. 